\title{
Cyclic behaviour of an unsaturated silty soil subjected to hydro- mechanical damage
}

\author{
Tomoyoshi Nishimura ${ }^{1, *}$ \\ ${ }^{1}$ Department of Civil Engineering, Ashikaga University, Tochigi, Japan
}

\begin{abstract}
The dynamic behaviour of unsaturated soil subjected to cyclic loading is considered using two stress state variables, net normal stress and matric suction. Though the influence of excess pore-water pressures in fully saturated soils has been investigated through experimental works for decades, it is significant in practice for unsaturated soil dynamic behaviour to be compared to saturated soil dynamic strength-deformation properties. Matric suction can be described as a scalar, which is useful in establishing safety factors and in mathematical simulations. This study focused on the dynamic behaviour of unsaturated soil leading to liquefaction failure. Solving practical problems requires considering the properties of unsaturated soil subjected to creep before introducing dynamic loading effects. This testing program consisted of a creep test and a cyclic loading test. Notably, a low suction range of soil structure is closely related to large deformations or leads to failure impacting the resistance of soil particle cohesion, including the macro-micro structure. Creep force was applied under lateral confining pressure, and suction measurements are indicating a gradual growth of excess pore-water pressure. Moreover, this study considered a dynamic triaxial compression test under the undrained condition for unsaturated soil with suction and creep history.
\end{abstract}

\section{Introduction}

The dynamic behaviour of unsaturated soil subjected to cyclic loading is considered using two stress variables net normal stress and matric suction. Bishop's equation for the effective stress of unsaturated soil, which has been accepted in the field of geotechnical mechanics, uses two stress variables as components. Matric suction can be described as a scalar, which is useful in the expansion and establishments of safety factors and mathematical simulations [1]. Though the influence of excess pore-water pressures in fully saturated soils has been investigated through experimental works for decades, it is significant in practice for unsaturated soil dynamic behaviour to be compared to saturated soil dynamic strength-deformation properties. The dynamic behaviour of unsaturated soils leading to complete failure is related to some factors such as matric suction, degree of saturation, void ratio, and degradation. Because deterioration causes strength to degrade, causing progressive liquefaction failure, these factors are of significant concern. Soil creep [2] caused by intense rainfall or water level changes results in a reduction of matric suction by increasing excess pore-water pressure. This creep behaviour should be measured continuously for pore-water pressure through experimental tests, as it is possible to evaluate the change in matric suction using a pressure plate technique [3, 4]. Creep behaviour leading to large deformation was in equilibrium relative to defined external loading, and unsaturated soil dynamic triaxial tests were conducted using a modified cyclic triaxial apparatus.

This study focused on the dynamic behaviour of unsaturated soil leading to liquefaction failure (i.e., leading to large deformations when undrained). Solving the practical problems mentioned above requires considering the properties of unsaturated soil that are subjected to creep progress before introducing dynamic loading efforts. This testing program consisted of a creep test and a cyclic loading test for matric suction control that were applied to the specimens. A silty soil was used, and a soil-water characteristic curve (SWCC) was measured prior to the tests using a pressure membrane technique to interpret the relationship between matric suction and the degree of saturation. Notably, a low suction range of soil structure is closely related to large deformation or leads to failures impacting the resistance of soil particle cohesion, including the macro-micro structure. When the wetting process (i.e. suction reduction) was consistently applied to the unsaturated soil specimen, the reduction of effective stress significantly impacted the strength of resistance. Subsequently, creep force was applied under lateral confining pressure, and suction measurements indicated a gradual growth of excess pore-water pressure. Moreover, this study considered a dynamic triaxial compression test under undrained condition for unsaturated soil with historical suction and creep application.

Corresponding author: tomo@ ashitech.ac.jp 


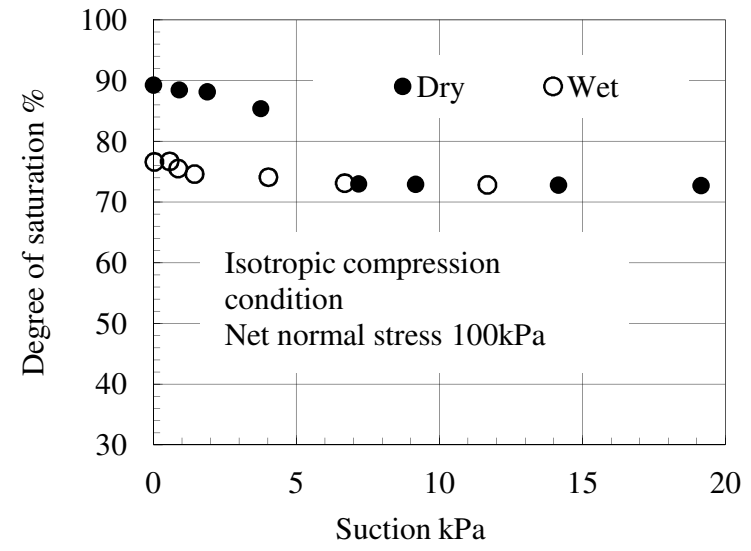

Fig. 1. Soil-water characteristic curve.

\section{Soil material and testing programs}

\subsection{Soil material}

This test program used silt with a relatively uniform distribution. The specimen notated as DL-clay had a fine content (particles smaller than $0.075 \mathrm{~mm}$ in diameter) of $99.0 \%$ by dry weight. The soil material had an optimum water content of $17.0 \%$ as obtained from the modified Proctor compaction test, which was conducted in five layers with 25 blows for each layer. The material has also been used previously in unsaturated soil mechanical research concerning shear strength, measurement of SWCCs, volume change properties, and seepage properties [5-8]. All of these experimental tests for unsaturated soil to control matric suction and high suction. Fig. 1 shows the SWCC that consists of changes in soil moisture in soil material against the application or measurement of suction. The SWCC in Fig. 1 involved a drying process and a wetting process until suction reached $20 \mathrm{kPa}$, as that degree of saturation indicated changes in the drying and wetting process in relatively small suction ranges. Hydro-mechanical properties were investigated for hysteresis to analyse the differences between drying and wetting,

The measurement of pore-water pressure in the prepared unsaturated soil specimen has often been ignored in experimental works. However, when attention is focused on unsaturated soil shear resistance, or when it is addressed in detail as a focal point of research, measuring the initial pore-water pressure in the soil specimen before conducting tests is essential. Previously, this study performed the measurement of pore-water pressure with a conventional method, in which the sample was placed on a triaxial pedestal base. The pedestal had a saturated microporous membrane [9] on the top surface, and the microporous membrane transferred hydraulic pressure from the soil specimen to a pressure transducer established in the triaxial apparatus.

One of the physical properties measured was hydraulic conductivity, and saturated soils were measured in conventional testing methods including the constant head

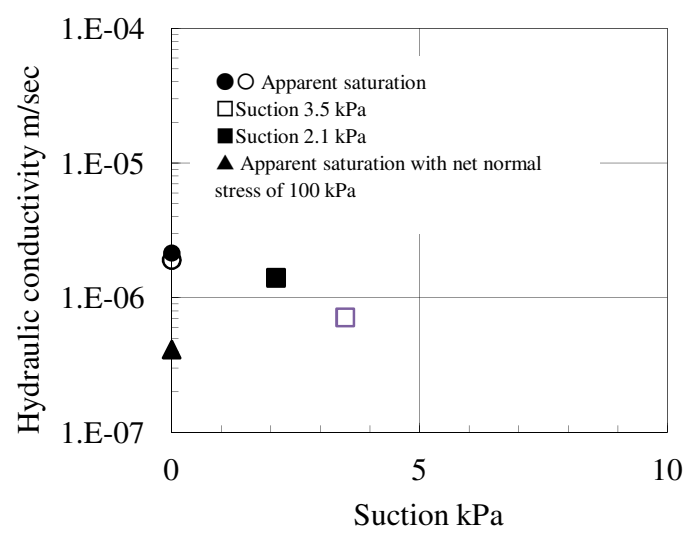

Fig. 2. Hydraulic conductivity with suction.

permeability test and the falling head permeability test, based on Darcy's law. It is not common to perform an unsaturated soil permeability test with a controlled matric suction. This system includes slight differences between the two tests, and this study describes the results of unsaturated soil permeability tests using an unsaturated soil conductivity apparatus with the possibility of control-ling matric suction. Fig. 2 shows that suction decreases the coefficient of permeability. When the suction value is zero, it means that the sample is in a saturated condition. The unsaturated permeability test was conducted using a small controlled suction, and the soil volume was maintained through the test. In the case of the black triangle symbol specifically, an isotropic confining pressure of $100 \mathrm{kPa}$ was applied to the specimen.

\subsection{Testing procedure}

Tests performed in this study included an unsaturated soil cyclic triaxial test, a creep test for unsaturated soil, and an unsaturated-saturated soil cyclic test. The unsaturated-saturated cyclic triaxial test used a modified cyclic triaxial apparatus that was specifically constructed for obtaining experimental results in this study. The apparatus was modified with additional elements including a vibrator, control equipment, a triaxial cell, and a supply system for cell pressure, pore-water pressure, and pore-air pressure with independent controls. The inner cell included a gap sensor used for measuring the volume change of the soil specimen. The gap sensor measured voltage changes, which can be translated to volume changes. In addition, a solenoidcontrolled valve was installed near the top cap connected to the pressure sensor. A double glass burette, installed with a differential pressure sensor, was connected to the triaxial cell. The pressure differential sensor measured the drainage or absorption of water from the specimen induced with suction.

The axis translation technique was used to apply matric suction to the soil specimen under constant net normal stress. A microporous membrane with an air 
entry value of $250 \mathrm{kPa}$ was installed into the modified pedestal. Limited experimental evidence was observed concerning measuring suction during cyclic loading. This apparatus was capable of applying the exact functions as mentioned above, and the unsaturatedsaturated soil cyclic triaxial test was shown to have been hitherto lacking in dynamic soil behaviour testing. This problem was investigated and verified using the results obtained from the apparatus.

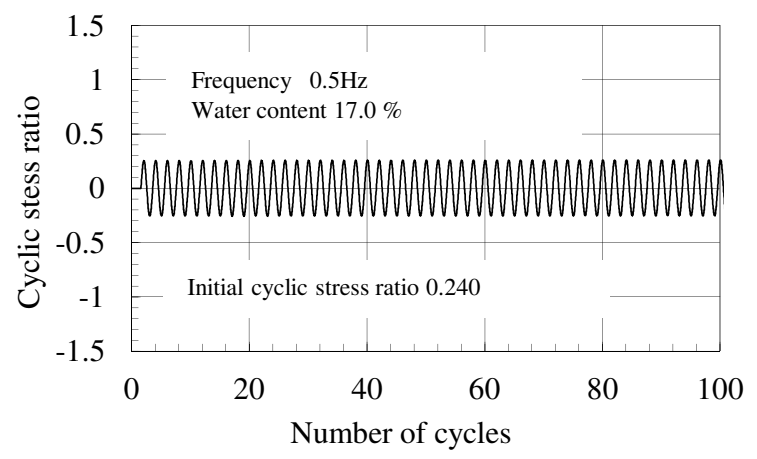

Fig. 3. Maintained cyclic stress ratio for water content $17.0 \%$.

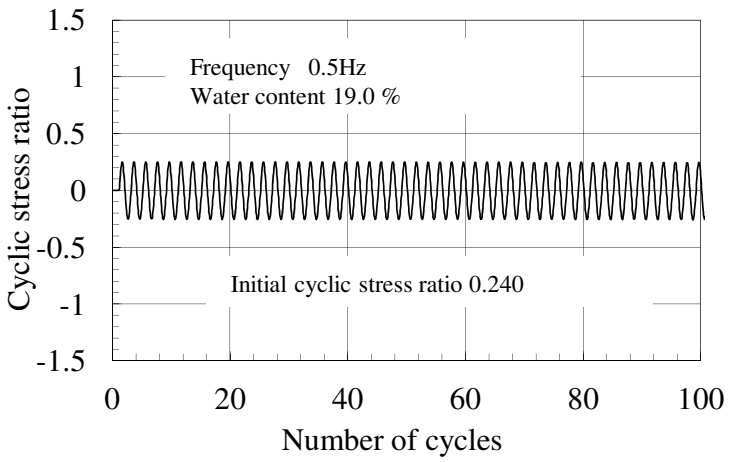

Fig. 4. Maintained cyclic stress ratio for water content $19.0 \%$.

\section{Test results}

\subsection{Cyclic loading behaviour for unsaturated soils}

Unsaturated soil triaxial tests were conducted to measure pore-air and pore-water pressures of unsaturated soils with cyclic loading. The physical properties of the specimen were as follows. Water contents ranged from $10.0 \%$ to $19.0 \%$, and specimens had a dry density of $1.387 \mathrm{~g} / \mathrm{cm}^{3}$ (i.e., equivalent to 0.911 in void ratio) for consistency. Specimen size was $10.0 \mathrm{~cm}$ in height with a diameter of $5.0 \mathrm{~cm}$. The initial cyclic stress ratio was 0.240 under a loading frequency of $0.5 \mathrm{~Hz}$, and the cyclic test was conducted 100 cycles. To measure the pore-air pressure and pore-water pressure, the use of two pore fluid pressures in unsaturated soil effective stresses was useful in ascertaining the association of suction to strength resistance under cyclic loading. It was reasonable to assume that the pore-air pressure in the voids was at equilibrium with atmospheric pressure by maintaining the drained pore air condition at the top cap. Pore-water pressure was measured on the surface of the pedestal, and a saturated microporous membrane was employed, fixed into the pedestal.

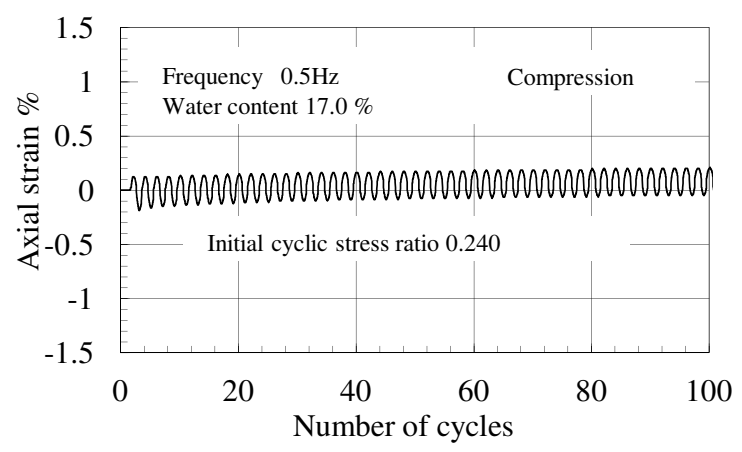

Fig. 5. Moving to compression side on axial strain.

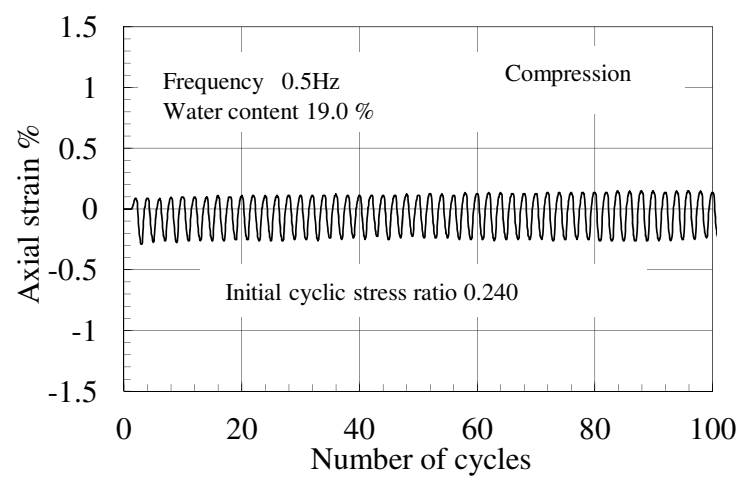

Fig. 6. Distinguished axial strain at the expansive side.

Cyclic loading began with a cyclic stress ratio of 0.240 for all specimens. Figs. 3 and 4 show the cyclic data sets for water contents of $17.0 \%$ and $19.0 \%$, respectively. Only a slight difference in cyclic stress ratio was observed, and it was considered to be almost negligible. Axial strain changes are shown in Figs. 5 and 6 , and contrasting relations with cyclic stress ratio were constant. In the case of water content of $17.0 \%$, deformation growth approached toward the compression side. However, the specimen maintained a constant difference between compression and expansion (i.e. amplitude was almost constant). For the entire duration of the test, no failure or large deformation occurred in the specimen. In the case of water content of $19.0 \%$, the tendency seemed to be similar to the axial strain data sets for the water content of $17.0 \%$, and no failure or large deformations were found, though the amplitude was slightly large in comparison to the water content of 17.0 $\%$. The relationship between water content and double amplitude axial strains are summarised and shown in Fig. 7. If deformations are correlated with the amount of water content, the effect of water content was verified in the cyclic behaviour in unsaturated soils. Excess porewater pressures of these specimens with different water content were measured during cyclic loading. 
For evaluation of excess pore-water pressures, suctions were calculated as shown in Fig. 8, indicating the water content both for the initial state and at the end of the test.

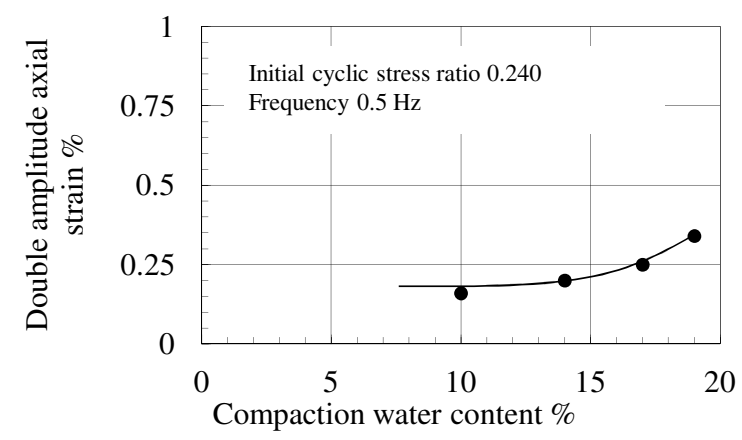

Fig. 7. Double amplitude strains at 100 cycles.

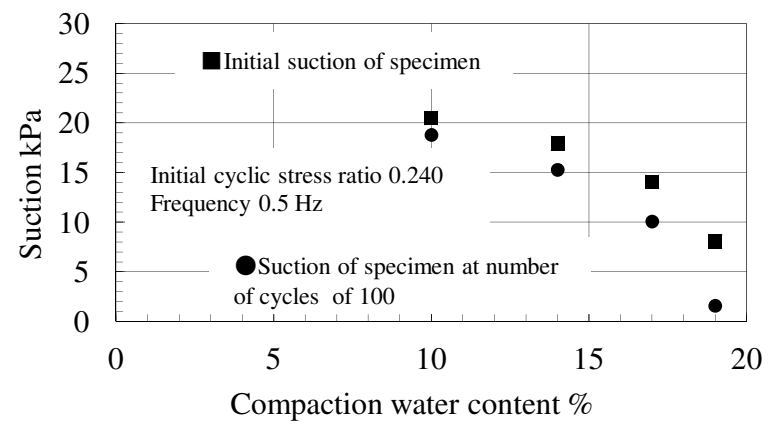

Fig. 8. Changing of suction due to cyclic loading.

It was considered that a reduction of suction strongly depends on water content. These results were possible to be observed in the curves. In particular, the largest reduction in suction occurred for the water content of $19.0 \%$

\subsection{Creep behaviour for unsaturated soils}

Unsaturated-saturated soil cyclic behaviour was a significant problem in geotechnical practice, and it was often attributed to seepage application in the ground or man-made structures due to rainfall. However, investigation of cyclic loading behaviour for fully saturated soils and the liquefaction phenomena in loose saturated sands have been widely attempted. This study focused on creep behaviour from a variety of circumstances associated with the stability of unsaturated ground to provide a more comprehensive characterisation for the evaluation of safety factors.

A creep test was conducted using the cyclic triaxial test apparatus as mentioned above, and deformations and changing of pore-water pressures were measured over long periods. A classical creep test was recognised for saturated clay soils. This test is meant to promote clarity in the unsaturated soil creep behaviour. In this creep test, all specimens were controlled as undrained conditions for measurement of negative or positive pore-water pressures. Creep tests were conducted at three different confining pressures that are $10 \mathrm{kPa}, 100 \mathrm{kPa}$ and 150 $\mathrm{kPa}$. The specimen displayed an initial suction of $30 \mathrm{kPa}$ when lateral confining pressure was $10 \mathrm{kPa}$. Specimens with the other two lateral confining pressures were controlled at $20 \mathrm{kPa}$ suction using the pressure membrane technique before applying the creep stress. The specimens remained under undrained condition when creep stresses were applied.

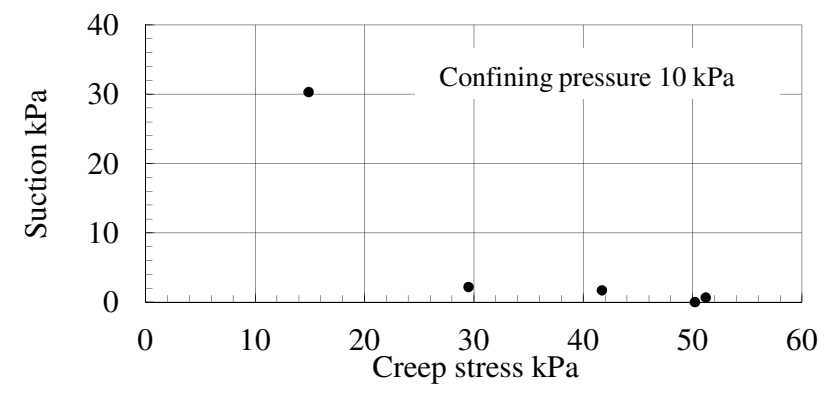

Fig. 9. Decrement of suction with creep stress.

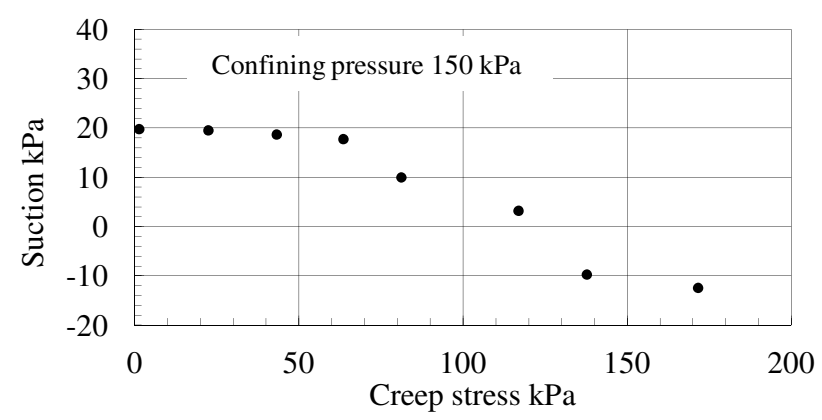

Fig. 10. Decrement of suction with creep stress.

Change of suction due to increment of creep stresses are shown in Figs 9 and 10 at confining pressures $10 \mathrm{kPa}$ and $150 \mathrm{kPa}$, respectively. The specimen at a lateral confining pressure of $10 \mathrm{kPa}$ showed that a considerable reduction in suction was produced around the initial suction. It was from $14.9 \mathrm{kPa}$ to $29.5 \mathrm{kPa}$ in creep stress. Subsequently, suction maintained slightly till the end of the test, and the remained suction was less than $0.7 \mathrm{kPa}$. Relationship between creep stress and suction was compared between $10 \mathrm{kPa}$ and $150 \mathrm{kPa}$ in confining pressures. Specimen with confining pressure of $150 \mathrm{kPa}$ indicated slightly reduction of suction till creep stress of $60 \mathrm{kPa}$. Also, negative pore-water pressure became to a positive value that suction value indicated is negative. The specimen used in the creep test was unsaturated, but specimen for the triaxial test was saturated soil. There were not coincident in the stress-strain relationship between unsaturated and saturated and could find out the difference.

Here, it was considered that the relationship among mean effective principal deviator stress and creep stress was established for confining pressure of $100 \mathrm{kPa}$. The effective stress paths are shown in Fig. 11 and the black circles are creep test results, and the thin black line is triaxial test results. Both data sets are very close, and the failure line is easily determined. The slope of the failure line is 1.339. The unsaturated specimen had a point on the defined failure line, which is a high stress value compared to the point of the saturated specimen. Also, strength parameters were evaluated from the failure line, 
and the angle of effective internal friction is 33.1 degrees, and effective cohesion was zero.

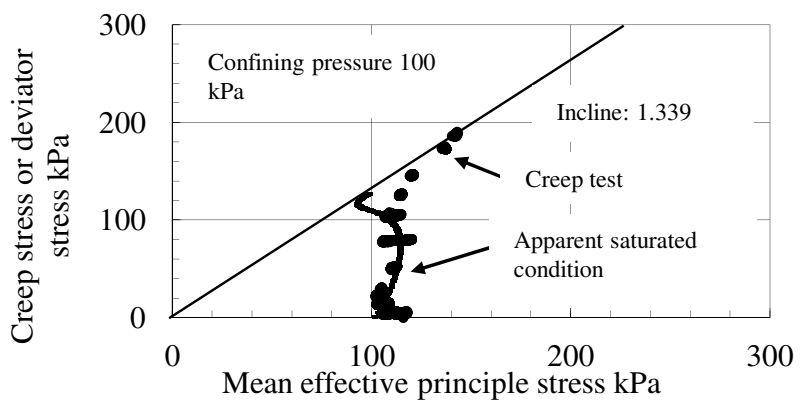

Fig. 11. Stress path at confining pressure of $100 \mathrm{kPa}$.

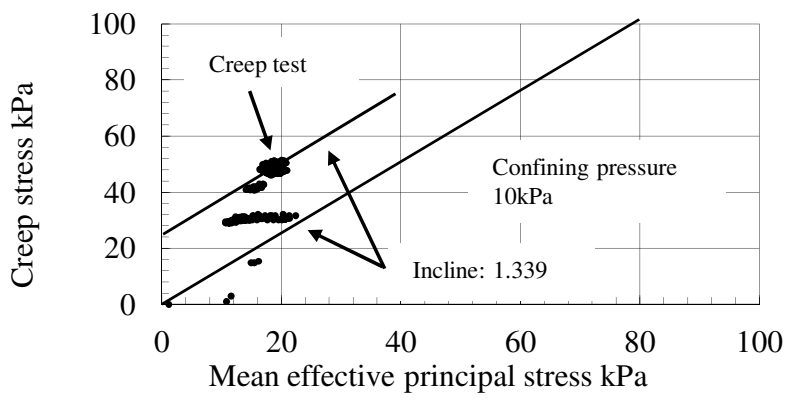

Fig. 12. Stress path at confining pressure of $10 \mathrm{kPa}$.

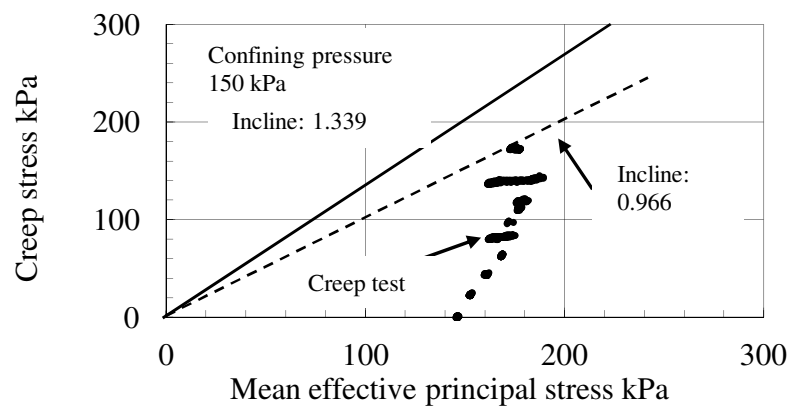

Fig. 13. Stress path at confining pressure of $150 \mathrm{kPa}$.

Data sets of creep test under confining pressure of both $10 \mathrm{kPa}$ and $150 \mathrm{kPa}$ are plotted in mean effective principal stress - deviator stress coordinate space and defined failure line in Fig. 11 is fitted. Two different effective stress paths are described in Figs. 12 and 13.

Effective stress path in creep behaviour of specimen was shown in Fig. 12 where lateral confining pressure of $10 \mathrm{kPa}$ was applied. Firstly, stress path approached quickly to failure line at the inception stage and passed through with remaining increasing. Stress condition at the end of the creep test is indicated on upper on failure line. Apparent cohesion of unsaturated soil was possible to estimate as around $22.0 \mathrm{kPa}$.

The relationship between mean effective principal stress and creep stress is shown in Fig. 13. For confining pressure of $10 \mathrm{kPa}$ the creep stress is some distance from the failure line at the end of creep test. It is due to the creep test axial strain range belong relatively small. (i.e. maximum axial strain of $8.0 \%$ ). If axial strain applied due to increase of creep stress is large, it is possible to identify an asymptote line. In addition, another line was indicated which linked between origin point and stress point at the end of the creep test. The slope of the straight line is 1.034, and the calculated strength parameters are as follows; effective angle of internal friction was 26.2 degrees and cohesion was zero. Then, obtained strength parameters were considered with that of apparently saturated samples, as shown in Fig. 11. Another straight line was indicated as a dashed line which passed through stress point having an axial strain of $8.0 \%$ in apparent saturated soil. The dashed line consists of a slope of 0.966 and intercept of zero. The obtained angle of internal friction was 24.6 degrees.

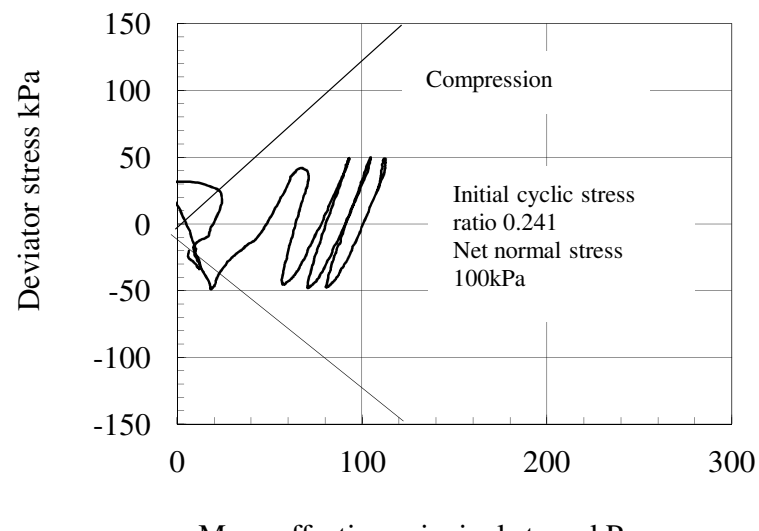

Mean effective principal stress $\mathrm{kPa}$

Fig. 14. Effective stress path at an initial stress ratio of 0.241 .

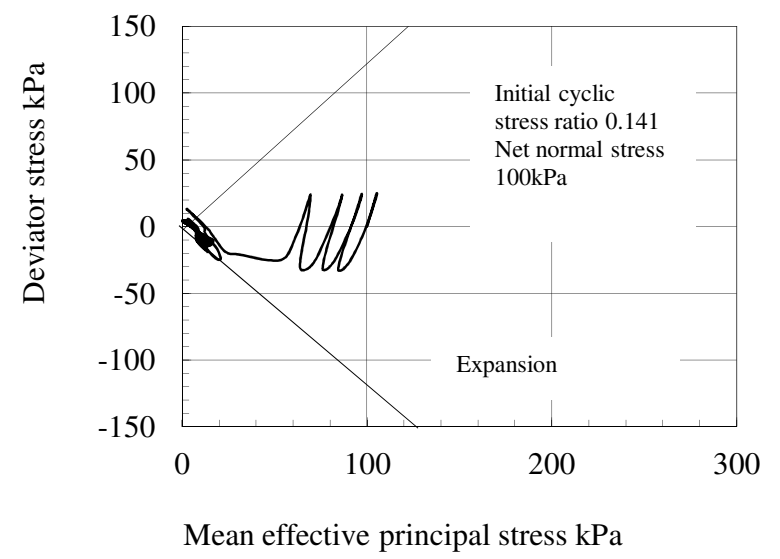

Fig. 15. Effective stress path at an initial stress ratio of 0.141 .

\subsection{Cyclic behaviour for apparently saturated soils}

The cyclic test process and conditions were already mentioned above. Obtained data sets were described in this section for two specimens with different initial water contents. The relationship between mean effective principal stress and deviator stress is described as the effective stress path in Figs. 14 and 15. In addition, the failure envelope confirmed liquefied stress conditions on cyclic loading, which were obtained from the monotonic undrained triaxial compression test. At the beginning of 
cyclic loading, the effective stress was decreased due to the development of excess pore water pressure, and mean effective principal stress rapidly decreased, approaching the origin point in coordinate space. The specimen reached the failure envelope on the dilation side, and it was destroyed or flowed. Similar behaviour occurred regardless of the initial cyclic stress ratio.

\section{Conclusions}

This study conducted dynamic triaxial compression tests for both unsaturated silty soil and apparent saturated silty soil. Also, the investigation was conducted for unsaturated silty soil with a creep test which was described using matric suction as one component of effective stress variables. A micro-porous membrane was used for measurement of pore-water pressure instead of ceramic disk. The obtained conclusions are as follows;

(1) Unsaturated silty soil indicated cyclic loading induced deformation and increment excess porewater pressure. Reduction of suction was large according to the increase in water content.

(2) Excess pore-water pressures occurred during creep stress loading, and suction associated with effective stress of unsaturated soil showed further reduction according to deformation. Severe changes of suction were produced at some creep stress. It seemed to be intertwined with multiple mechanical parameters.

(3) Before dynamic loading, unsaturated soil showed decreasing suction due to the reduction of effective stress. Probably, the unsaturated soil subjected to creep stress described cyclic loading behaviour for apparently saturated soil.

\section{References}

1. D. G. Fredlund, H. Rahardjo, Chapter 4, Measurement of Soil Suction, Soil Mechanics for Un-saturated Soils, A Wiley-Interscience Publication, JOHN WILEY \& SONS, INC, 64-106 (1993).

2. A. W. Bishop, Creep characteristics of two undisturbed clays, Proceedings of the 7th International Conference on Soil mechanics, Mexico, 1, 29-37 (1969).

3. X. L. Lai, S. M. Wang,W. M. Ye, Y. Y. Cui, Experimental investigation on the creep behavior of an unsaturated clay, Canadian Geotechnical Journal, 51, 6, 621-628 (2014).

4. T. Nishimura, J. Koseki, Accumulated vertical strain without confining pressure for compacted bentonite due to hydration effort, The 8th International Congress on Environmental Geotechnics, 2, 414420 (2018).

5. P. Habasimbi, T. Nishimura, Comparison of soilwater characteristic curves in one-dimensional and isotropic stress conditions, Soil system MDPI, Open
Access Journal, 2, 43, (https://www.mdpi.com/2571-8789/2/3/43)

6. C. W. W. Ng, L. T. Zhan, Y. J. Cui, A new simple system for measuring volume changes in unsaturated soils, Canadian. Geotechnical Journal, 39, 757-764 (2002).

7. H. Wang, J. Koseki, T. Nishimura, SWCC measurement of two types of iron ores, Proc. 6th Int. Conf. on unsaturated soils, Unsat2014, Sydney, 973979 (2014).

8. H. Wang, T. Sato, J. Koseki, G. Chiaro, J. Tan Tian, J. A system to measure volume change of unsaturated soils in undrained cyclic triaxial tests, Geotechnical Testing Journal, 39, 4, 532-542 (2016).

9. T. Nishimura, J. Koseki, D. G. Fredlund, H. Rahardjo, Microporous membrane technology for measurement of soil-water characteristic curve. Geotechnical Testing Journal, 35, 201-208 (2012). 